\title{
Association of variants in selected genes mediating host immune response with duration of Staphylococcus aureus bacteremia
}

\author{
Tonia C. Carter ${ }^{1} \cdot$ Zhan Ye ${ }^{1}$ Lynn C. Ivacic ${ }^{2} \cdot$ Noah Budi $^{3} \cdot$ Warren E. Rose ${ }^{3}$ Sanjay K. Shukla $\mathbb{E}^{1}$
}

Received: 9 January 2020 / Revised: 12 May 2020 / Accepted: 18 May 2020 / Published online: 8 June 2020

(c) The Author(s), under exclusive licence to Springer Nature Limited 2020

\begin{abstract}
Host genetic variation may be a contributing factor to variability in Staphylococcus aureus bacteremia duration. We assessed whether 28 single nucleotide polymorphisms (SNPs) in seven genes (TLR2, TLR4, TIRAP, IRAK4, TRAF6, NOD2, and $\mathrm{CISH}$ ) that mediate host immune response were associated with $S$. aureus bacteremia duration. Subjects included 158 patients with short-term ( $\leq 4$ days) and 44 with persistent ( $>4$ days) $S$. aureus bacteremia from an academic medical center. In single SNP analyses, the minor allele frequencies of three TIRAP SNPs (rs655540, rs563011, and rs8177376) were higher in persistent bacteremia $(P<0.05)$. A haplotype with all three minor alleles was also associated with persistent bacteremia $(P=0.037)$. The minor allele frequencies of four other TIRAP SNPs (rs8177342, rs4937114, rs3802813, and rs4937115) were higher in short-term bacteremia $(P<0.05)$, and a haplotype containing the four minor alleles was associated with shortterm bacteremia $(P=0.045)$. All seven SNPs are located in binding sites for proteins or noncoding RNAs that regulate transcription. None of the associations remained statistically significant after adjustment for multiple comparisons. Further investigation is needed to understand how genetic variation in TIRAP and other host immune genes may influence the duration of $S$. aureus bacteremia.
\end{abstract}

\section{Introduction}

Staphylococcus aureus is one of the most common bacterial pathogens in human bloodstream infections and is more strongly associated with mortality than any other bacterial pathogen [1-4]. It uses a variety of virulence factors including pore forming toxins [5] and adhesion factors during infections and pathogenesis [6, 7]. These virulence factors are destined to interact with a variety of host cell receptors and signaling pathways; therefore, genetic

Supplementary information The online version of this article (https:// doi.org/10.1038/s41435-020-0101-0) contains supplementary material, which is available to authorized users.

Sanjay K. Shukla

shukla.sanjay@mcrf.mfldclin.edu

1 Center for Precision Medicine Research, Marshfield Clinic Research Institute, Marshfield, WI, USA

2 Integrated Research and Development Laboratory, Marshfield Clinic Research Institute, Marshfield, WI, USA

3 School of Pharmacy, University of Wisconsin-Madison, Madison, WI, USA susceptibility to $S$. aureus bacteremia (SAB) is likely to be complex [8, 9]. Patients with SAB experience a wide spectrum of disease duration, severity, and clinical outcomes [10]. This heterogeneity is probably influenced, in part, by host genetic susceptibility but the relative contribution of host genetic variation is both understudied and poorly understood, especially in relation to $\mathrm{SAB}$ acquisition and bacteremia duration $[11,12]$.

First-degree relatives of patients with $\mathrm{SAB}$ are likely to have a significantly higher $\mathrm{SAB}$ incidence ratio compared with the general population, suggesting a genetic risk [13]. Further, several reports suggest that host genetic variation may be a contributing factor to bacteremia susceptibility. A segment of chromosome 6 that harbors the human leukocyte antigen class II region, shown to have roles in modulating immune responses, seems to be associated with susceptibility to SAB [14]. The glutamine-regulating glutaminase 2 gene, GLS2, which has roles in regulating plasma glutamine levels and modulating adaptive immune response, has been reported to be correlated with development of complicated SAB [15]. A genome-wide association study found that alleles at four single nucleotide polymorphisms (SNPs) on chromosome 3 were suggestive of a protective effect against acquisition of infective endocarditis with SAB [12]. Indeed, the rs 8060974 variant in VAC14, encoding 
phosphoinositide-regulating protein, is associated with genetic susceptibility to bacteremia from nontyphoidal Salmonella, Streptococcus pneumonia, Escherichia coli, and Acinetobacter spp. in Kenyan children [16].

Much of the knowledge on host genetic signaling pathways and Toll-like receptor genes in S. aureus infection has come from studies of skin and soft tissue infections [17, 18]. These pathways in skin and soft tissue infections point to roles for Toll-like receptor 2 (TLR2), Toll-like receptor 4 (TLR4), TIR domain containing adapter protein $(T I R A P)$, interleukin 1 receptor associated kinase 4 (IRAK4), TNF receptor associated factor 6 (TRAF6), nucleotide binding oligomerization domain containing 2 (NOD2), cytokine inducible $\mathrm{SH} 2$ containing protein $(\mathrm{CISH})$, and myeloid differentiation primary response protein $88(M y D 88)$ in host defense against infection and inflammation [18-22].

We hypothesized that the minor alleles of putative SNPs may disrupt the function or expression of key inflammatory genes responsible for competent host response to $\mathrm{SAB}$. In this study, we determined whether potentially functional SNPs in TLR2, TLR4, TIRAP, IRAK4, TRAF6, NOD2, and $\mathrm{CISH}$ are associated with short-term or prolonged SAB.

\section{Results}

The range and median (inter-quartile range) for the number of days of bacteremia are shown in Table 1. Length of bacteremia was not significantly different by source of infection, when compared with the Wilcoxon rank sum test $(P=0.26)$. Study subjects were nonpolymorphic for two SNPs (TLR2 rs116232047 and TLR4 rs5030719), and these SNPs were excluded from further analyses. Table 2 shows the remaining 28 SNPs, their predicted functional effect, and their minor allele frequencies. The minor alleles of three TIRAP SNPs (rs655540, rs563011, and rs8177376) were more frequent in persistent than short-term SAB $(P<0.05$ nominally significant). The three SNPs are in strong linkage disequilibrium with each other $\left(r^{2} \geq 0.94, \quad D^{\prime}=1\right)$

Table 1 Duration of $S$. aureus bacteremia.

\begin{tabular}{lrlc}
\hline Subjects & $n$ & \multicolumn{2}{l}{ Duration of bacteremia (days) } \\
\cline { 3 - 4 } & & Range & $\begin{array}{l}\text { Median } \\
\text { (inter-quartile range) }\end{array}$ \\
\hline All & 202 & $1-441$ & $2(1-3.75)$ \\
Persistent bacteremia & 44 & $5-441$ & $8.5(6.75-26)$ \\
Infection source & & & \\
$\quad$ Endocarditis & 46 & $1-79$ & $2(1-3)$ \\
$\quad$ Skin/soft tissue infection & 128 & $1-277$ & $2(1-4)$ \\
$\quad$ Catheter/other medical device & 27 & $1-441$ & $2(1-2.5)$ \\
\hline
\end{tabular}

(Supplementary Figure). The minor alleles of another four TIRAP SNPs (rs8177342, rs4937114, rs3802813, and rs4937115) were more frequent in short-term than persistent SAB (Table 2; $P<0.05$ nominally significant). These four SNPs are in strong linkage disequilibrium with each other $\left(r^{2} \geq 0.87, D^{\prime}=1\right)$ but not with the three TIRAP SNPs mentioned above $\left(r^{2}<0.05\right)$ (Supplementary Figure). None of the 13 TIRAP SNPs had minor allele frequencies that were significantly different between patients with short-term $\mathrm{SAB}$ and the Genome Aggregation Database European ancestry population (Table 2). The minor allele frequencies of three TLR4 SNPs (rs5030724, rs5030718, and rs200020265), two NOD2 SNPs (rs5743279 and rs2066847), and TRAF6 rs200798752 were higher in patients with short-term SAB compared with the Genome Aggregation Database European ancestry population (Table $2 ; P<0.05$ nominally significant) but none of these SNPs was associated with SAB duration.

A global test to determine whether the distribution of haplotypes in each gene differed between the short-term and persistent SAB groups generated $P$ values of 0.82 for $C I S H$, 0.91 for NOD2, 0.25 for TLR2, and 0.22 for TLR4, and 0.016 (nominally significant) for $T I R A P$, indicating that the overall distribution of TIRAP haplotypes differed significantly between the two groups prior to adjustment for multiplicity. When individual haplotype frequencies were compared between the short-term and persistent $\mathrm{SAB}$ groups, the TIRAP CCGGGACGCGGCA minor haplotype was more common in persistent than short-term SAB (Table 3; $P=0.037$ nominally significant). This haplotype contained the minor alleles of all three SNPs nominally associated with persistent SAB in Table 2. In addition, the TCTGGACGCGTCA major haplotype and the TGTGTACGCATCG minor haplotype in TIRAP occurred more frequently in short-term than persistent SAB (Table 3; $P<0.05$ nominally significant). The minor TGTGTACGCATCG haplotype, but not the major haplotype, had minor alleles for all four SNPs associated with short-term $\mathrm{SAB}$ in Table 2. In haplotype analyses that treated SAB duration as a quantitative trait, another minor TIRAP haplotype (TCTGGGCGCGTCA) was nominally associated with decreasing SAB duration (Table 3; $P=0.032$ nominally significant). The major TIRAP haplotype and the latter, minor TCTGGGCGCGTCA haplotype lacked the minor alleles for the three SNPs associated with persistent SAB in Table 2. A group of ten rare, minor TIRAP haplotypes were also nominally associated with $\mathrm{SAB}$ duration, but because rare haplotypes can generate unstable effect estimates, we did not attempt to describe the effects of individual rare haplotypes. Haplotypes in CISH, NOD2, TLR2, and TLR4 were not associated with SAB duration. None of the associations observed in the single SNP or haplotype analyses was statistically significant after adjustment for multiple comparisons. 


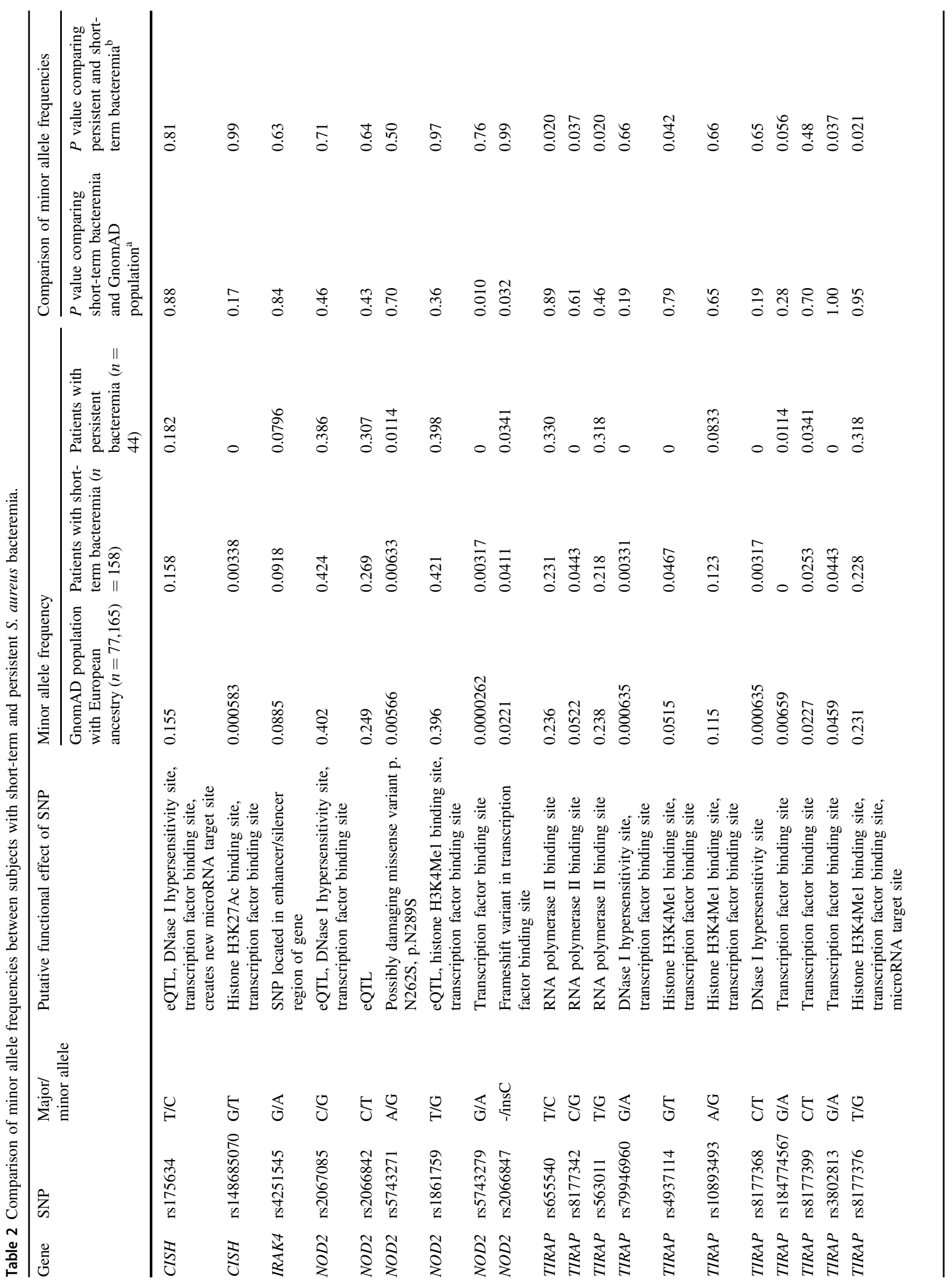




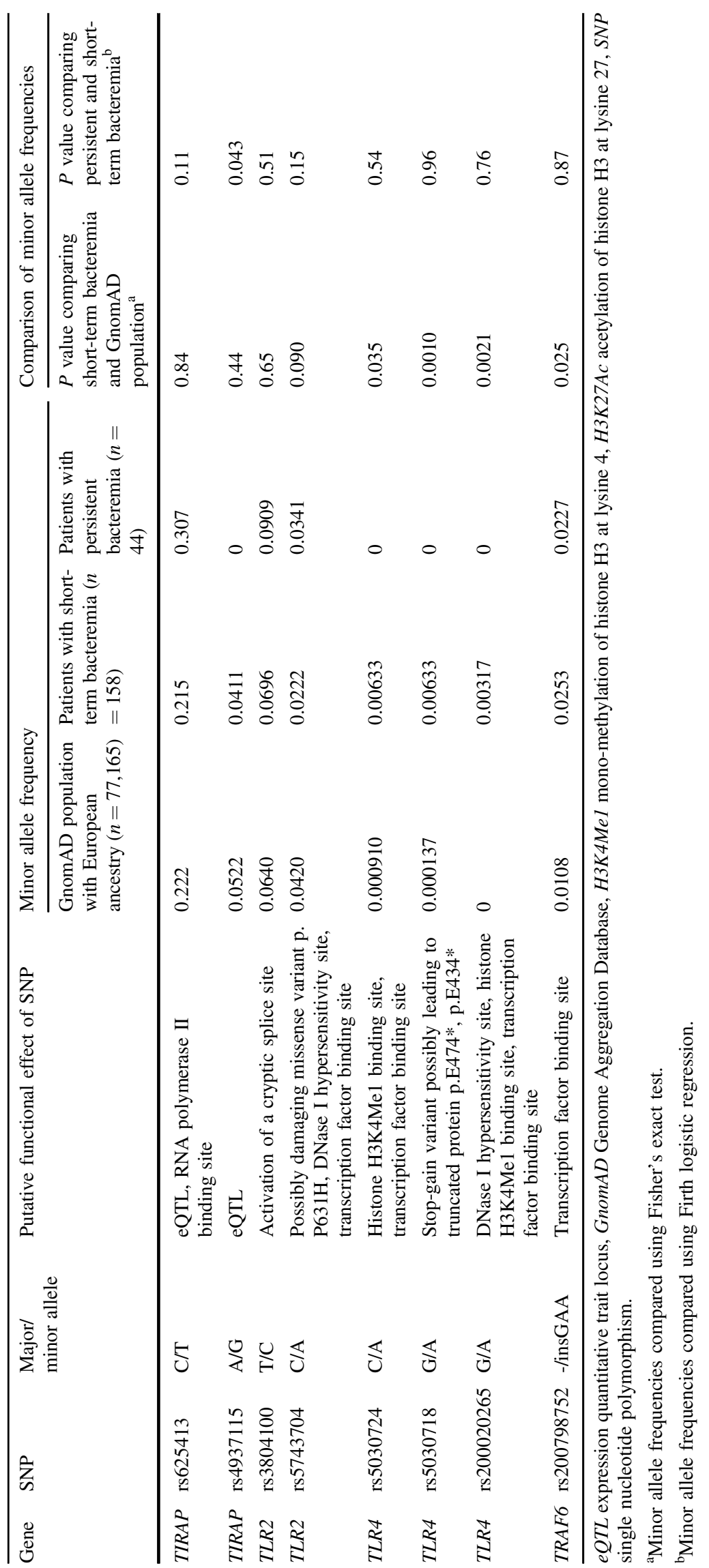


Table 3 Haplotype analysis of number of days of infection treated as a binary variable or a quantitative trait.

\begin{tabular}{|c|c|c|c|c|c|c|}
\hline \multirow[t]{2}{*}{$\overline{\text { Gene }}$} & \multirow[t]{2}{*}{ Haplotypes $^{\mathrm{a}}$} & \multicolumn{3}{|c|}{$\begin{array}{l}\text { Haplotype frequency in subjects with } \\
\text { S. aureus bacteremia }\end{array}$} & \multirow{2}{*}{$\begin{array}{l}P \text { value comparing haplotype } \\
\text { frequency between persistent } \\
\text { and short-term bacteremia }\end{array}$} & \multirow[t]{2}{*}{$\begin{array}{l}P \text { value from quantitative } \\
\text { trait analysis }\end{array}$} \\
\hline & & $\begin{array}{l}\text { All subjects } \\
(n=202)\end{array}$ & $\begin{array}{l}\text { Persistent bacteremia } \\
(n=44)\end{array}$ & $\begin{array}{l}\text { Short-term bacteremia } \\
(n=158)\end{array}$ & & \\
\hline \multirow[t]{3}{*}{$\mathrm{CISH}$} & Major: TG & 0.837 & 0.818 & 0.842 & 0.84 & Ref \\
\hline & Minor: CG & 0.166 & 0.207 & 0.154 & 0.78 & 0.073 \\
\hline & All others (2 haplotypes) & 0.00269 & 0 & 0.00344 & NA & 0.80 \\
\hline \multirow[t]{6}{*}{ NOD2 } & Major: GCAGG- & 0.398 & 0.375 & 0.408 & 0.81 & Ref \\
\hline & Minor: CCAGG- & 0.0126 & 0.0114 & 0.0129 & 0.97 & 0.87 \\
\hline & CCATG- & 0.291 & 0.295 & 0.290 & 0.92 & 0.68 \\
\hline & CTATGC & 0.0367 & 0.0341 & 0.0373 & 0.94 & 0.44 \\
\hline & CTATG- & 0.236 & 0.273 & 0.222 & 0.53 & 0.47 \\
\hline & All others (11 haplotypes) & 0.0254 & 0.0114 & 0.0294 & NA & 0.30 \\
\hline \multirow[t]{17}{*}{ TIRAP } & Major: TCTGGACGCGTCA & 0.371 & 0.294 & 0.391 & 0.020 & Ref \\
\hline & Minor: CCGGGACGCGGCA & 0.230 & 0.307 & 0.212 & 0.037 & 0.052 \\
\hline & TCTGGACGCGTTA & 0.226 & 0.273 & 0.212 & 0.27 & 0.61 \\
\hline & TCTGGGCGCGTCA & 0.0860 & 0.0470 & 0.0968 & 0.29 & 0.032 \\
\hline & TCTGGGCGTGTCA & 0.0272 & 0.0341 & 0.0253 & 0.54 & 0.43 \\
\hline & TGTGTACGCATCG & 0.0322 & 0 & 0.0411 & 0.045 & 0.14 \\
\hline & All others (10 haplotypes): & & & & & \\
\hline & CCGAGATGCGGCA & 0.00248 & 0 & 0.00316 & NA & 0.035 \\
\hline & CCTAGACGCGGCA & $1.80 \mathrm{E}-04$ & 0 & 0.00226 & NA & \\
\hline & CCTAGACGCGTCA & 0.00270 & 0 & 0.00188 & NA & \\
\hline & CCTGGACGCGGCA & 0.00311 & $2.00 \mathrm{E}-05$ & 0.00407 & NA & \\
\hline & CCTGGACGCGGTA & 0.00285 & 0.0113 & 0 & NA & \\
\hline & CCTGGACGCGTCA & 0.00472 & 0.0114 & 0.00128 & NA & \\
\hline & CGGGTACGCAGCA & 0.00248 & 0 & 0.00316 & NA & \\
\hline & TCGGGACGCGTTA & 0.00248 & 0.0114 & 0 & NA & \\
\hline & TCTGGACGCGGCA & $5.20 \mathrm{E}-04$ & 0 & 0.00158 & NA & \\
\hline & TCTGGGCGCGGCA & 0.00196 & 0 & 0.00158 & NA & \\
\hline \multirow[t]{3}{*}{ TLR2 } & Major: TC & 0.901 & 0.875 & 0.908 & 0.22 & Ref \\
\hline & Minor: $\mathrm{CC}$ & 0.0743 & 0.0909 & 0.0696 & 0.54 & 0.18 \\
\hline & $\mathrm{TA}$ & 0.0248 & 0.0341 & 0.0222 & 0.14 & 0.39 \\
\hline \multirow[t]{2}{*}{ TLR4 } & Major: CGG & 0.987 & 1.000 & 0.984 & 0.22 & Ref \\
\hline & Minor: All 3 minor haplotypes & 0.0146 & 0.0109 & 0.0157 & NA & 0.42 \\
\hline
\end{tabular}

$N A$ a $P$ value was not available because $P$ values were not calculated when a haplotype was very rare in both subject groups.

${ }^{\text {a }}$ The order of alleles in each haplotype is according to the order of the SNPs listed for each gene in Table 2.

\section{Discussion}

This study evaluated whether human immune genetic polymorphisms were associated with duration of SAB. Previous studies have investigated the role of human genetics on susceptibility to $S$. aureus skin infections [23-25]; however, acquisition of SAB is complicated and may be more driven by multiple factors including medical complications such as comorbidities, procedures, and hospitalizations [26]. This study focused on a small number of host genes, which have been described to play a role in $S$. aureus infections and pathogenesis. Specifically, the duration of bacteremia may be affected by variants present in the genes studied.

Findings from single SNP and haplotype analyses indicated that the minor alleles of seven TIRAP SNPs were nominally associated with duration of SAB. Of the three
SNPs that had minor alleles nominally associated with persistent SAB, two (rs655540 and rs563011) are located within two kilobase pairs upstream of the TIRAP transcription start site, in the TIRAP promoter region, and the third SNP (rs8177376) is in the TIRAP 3'-untranslated region. Two of the four TIRAP SNPs that had minor alleles nominally associated with a shorter duration of SAB (rs8177342 and rs4937114) are also located in the TIRAP promoter region. Another SNP, rs3802813, is a missense variant (p.S55N) predicted by SIFT [27] and PolyPhen-2 [28] to be tolerated, and the fourth SNP, rs4937115, is 461 base pairs downstream of TIRAP. This indicates that six of the seven SNPs are located in regions often populated by gene regulatory elements: the gene promoter region, the 3 untranslated region, and the region immediately downstream of the gene. All seven SNPs are also located at sites predicted to be involved in transcriptional regulation, 
including sites that bind RNA polymerase II (the polymerase responsible for mRNA synthesis in eukaryotic organisms), transcription factors, or the histone protein $\mathrm{H} 3 \mathrm{~K} 4 \mathrm{me} 1$ (histone $\mathrm{H} 3$ protein mono-methylated at the fourth lysine residue), often found near genomic regulatory elements [29]. Further, SNP rs8177376 is predicted to be in a conserved binding site for miRNAs, noncoding RNAs that function in the posttranscriptional control of gene expression. The minor alleles of the three SNPs nominally associated with persistent $\mathrm{SAB}$ often occurred on the same haplotype and, similarly, the minor alleles of the four SNPs associated with short-term SAB were frequently on the same haplotype; therefore, it is possible that SNPs on the same haplotype contribute to a concerted effect on the regulation of TIRAP gene expression, if the SNPs have functional consequences as predicted.

Previous reports have investigated associations between disease outcomes and three (rs655540, rs3802813, and rs8177376) of the seven SNPs, and some of these reports suggest that variant rs 8177376 is associated with immunerelated conditions. The major TT genotype of TIRAP rs8177376 was significantly more frequent in Brazilian patients with Chagas disease (trypanosomiasis), caused by infection with the protozoan Trypanosoma cruzi, compared with infected individuals who remained disease-free and asymptomatic [30]. This association remained significant when cases were restricted to severe disease, chronic Chagas cardiomyopathy with a left ventricular ejection fraction under $40 \%$. The level of IL-10, an anti-inflammatory cytokine, secreted from peripheral blood mononuclear cells after in vitro stimulation with measles virus was significantly higher in cells from individuals with the rs8177376 minor GG genotype [31]. Subjects were children or young adults of European ancestry who had documentation of having received two doses of measles-mumps-rubella vaccine. In a study in the Netherlands that included 1-year-old children who had been vaccinated four times with whole cell pertussis vaccinecontaining diphtheria-tetanus-pertussis-polio-Haemophilus influenzae type $\mathrm{B}$ vaccine, pertussis toxin-specific immunoglobulin $\mathrm{G}$ titers were lower in children with the rs8177376 minor GG genotype [32]. However, the study reported that this association did not survive controlling for multiple testing by false discovery rate analysis. Other reports observed no statistically significant associations between rs8177376 and prostate cancer mortality [33], rs655540 and severe adolescent idiopathic scoliosis [34], and rs3802813 and Chlamydia trachomatis infection in pelvic inflammatory disease [35], sepsis-associated acute lung injury [36], urinary tract infections [37], or meningeal tuberculosis [38].
Strengths of this study were its focus on potentially functional SNPs and the wide range of bacteremia duration of study participants. Further, this research addressed an understudied but medically important topic. However, the study was limited by the small number of genes and SNPs tested and the small sample size of participants. None of the associations with length of bacteremia survived correction for multiple comparisons; therefore, the results provide only suggestive evidence pointing to certain host genes that should be further investigated for a role in $\mathrm{SAB}$ duration. We adjusted for multiple comparisons to avoid reporting false-positive associations, but this adjustment posed a hurdle to identifying statistically significant associations in this small study. The nominally significant associations we observed suggested that predicted functional variation in TIRAP may contribute to $\mathrm{SAB}$ duration by regulating gene expression, and the study identified TIRAP as a promising candidate for further investigation of the role of host immune genes in SAB duration. However, the preliminary findings of this pilot study require confirmation by others, and future studies should address whether the findings are generalizable to nonEuropean study populations.

In conclusion, potentially functional SNPs in TIRAP and genes involved in the activation and modulation of the host inflammatory response to microbial pathogens may be associated with SAB duration. Identifying host genetic variants that influence the response to microbial infection could improve understanding of the variable clinical course of $\mathrm{SAB}$ and assist in defining optimal precision medicine approaches to treatment, but additional research is needed to identify the genes involved and characterize the nature and magnitude of the functional effects of the variants.

\section{Materials/subjects and methods}

\section{Subjects}

Two hundred and two patients diagnosed with, and treated for, SAB at UW Health, a 505-bed academic medical center in Madison, WI, USA, were enrolled. Subjects included 158 patients with short-term SAB ( $\leq 4$ days) and 44 with persistent SAB ( $>4$ days), as previously defined $[39,40]$. Four days was chosen as the cut-point for persistent $\mathrm{SAB}$ because $\mathrm{SAB}$ duration longer than 4 days is associated with poor outcomes such as metastatic infection, complications, and increased mortality [40]. All patients were of European ancestry. Study participants provided written informed consent in accordance with the Declaration of Helsinki. This study was approved by 
the Institutional Review Boards of Marshfield Clinic Research Institute and University of WI, Madison.

\section{Genes and SNP selection}

Because knowledge about the host genetics of bacteremia is limited, we started by selecting genes reported to be associated with bacteremia and/or sepsis caused by other pathogens and genes that are known to have a role in skin and soft tissue infections caused by $S$. aureus [23, 41-47]. Thirty SNPs in TLR2, TLR4, TIRAP, IRAK4, TRAF6, $N O D 2$, and $C I S H$ were selected. Only SNPs in the promoter, coding, 5'-untranslated region, or 3'-untranslated region of these genes and that had an allele frequency $>$ 0.0005 as compiled from the dbSNP database were investigated. SNPs with the highest allele frequency were selected first. Information on predicted functional effects was obtained from annotations in the Ensembl Genome Browser [48] and from ENCODE [49] and Open Regulatory Annotation [50] data available through the University of California, Santa Cruz Genome Browser, the PolymiRTS Database 3.0 of miRNA target sites [51], and the published literature $[52,53]$.

\section{DNA sample collection and SNP genotyping}

DNA was extracted from archived patient blood samples collected on the day of bacteremia presentation and stored at $-80^{\circ} \mathrm{C}$ until analysis. DNA quantity was measured using a NanoDrop spectrophotometer (ThermoFisher Scientific, Carlsbad, CA, USA) and DNA quality was determined by the A260/280 ratio. Genotyping of SNPs was performed completely blinded to the duration of SAB in patients. SNPs were genotyped on the MassARRAY system (Agena Bioscience, San Diego, CA, USA). Three multiplexed assays (23-plex, 14-plex, and 18-plex) were designed representing targeted areas in the seven genes. The multiplex assay utilized the iPLEX assay, a primer extension reaction chemistry designed to detect sequence differences at the single nucleotide level. Each sample was amplified in a multiplexed reaction, and then a specific primer, dependent on the template sequence, was extended. The assay was validated by testing HapMap-CEU samples so that the genotyping results could be compared with the previous results. Additional details of the genotyping method are described in Supplementary Material. Genotyping primers (forward, reverse and extend), genes, and SNPs are listed in the Supplementary Table. The genotype call rates were $92.8 \%, 95.2 \%, 94.7 \%$, and $97.6 \%$ for SNPs rs 148685070 , rs79946960, rs4937114, and rs10893493, respectively, and $100 \%$ for the other 26 SNPs. Genotype distributions at all SNPs were consistent with Hardy-Weinberg equilibrium $(P>0.001)$.

\section{Statistical analysis}

Minor allele frequencies were compared between patients with short-term and persistent $\mathrm{SAB}$ using Firth logistic regression in the $\mathrm{R}$ software program [54]. Covariates included in regression models were selected patient clinical characteristics: age at infection, dialysis (yes/no), cardiovascular disease (yes/no), diabetes mellitus (yes/no), immune dysfunction (yes/no), use of appropriate antibiotic for $S$. aureus bacteremia (yes/no according to guidelines based on standard-of-care), methicillin-resistant $S$. aureus (yes/no), and source of infection (endocarditis, skin/soft tissue infection, or catheter/other medical device). Because the short-term SAB group was used as a reference group in these comparisons, this group was also compared with the European ancestry (non-Finnish and Finnish; $n=77,165$ ) population in the Genome Aggregation Database (https:// gnomad.broadinstitute.org/) to determine whether minor allele frequencies in our reference group were similar to those in the general European ancestry population. Allele frequencies were compared using Fisher's exact test in PLINK [55].

A haplotype analysis was performed for five genes (TLR2, TLR4, TIRAP, NOD2, and CISH) in which multiple SNPs were assayed. For each gene, the genotypes were phased to obtain haplotypes for each study participant, and haplotype analyses were performed using two approaches: one considering SAB duration as a binary trait (short-term versus persistent) and the other considering $\mathrm{SAB}$ duration as a quantitative trait (bacteremia duration defined by time to definitive negative culture [40]). Two different approaches were employed because of uncertainty about the clinical relevance of defining SAB duration as a binary or continuous variable. For the binary trait approach, haplotype frequencies were compared between short-term and persistent $\mathrm{SAB}$ using $2 \times 2$ contingency tables. For the quantitative trait approach, linear regression was used to compare minor haplotypes with the major haplotype (considered the reference haplotype) as predictors of number of days of bacteremia. Data on number of days of infection were not normally distributed and hence were logtransformed for linear regression analysis. Covariates included in haplotype analyses were the same as those included in Firth logistic regression models. All rare, minor haplotypes in a gene were grouped together for comparison with the major haplotype in linear regression analysis. The haplotype analyses were performed using the HaploStats package in R [56]. $P$ values $<0.05$ were considered as nominally significant, and the Benjamini-Hochberg method was used to adjust for multiple comparisons.

Funding This study was supported by a pilot grant award from the Institute of Clinical and Translational Research at the University of 
Wisconsin-Madison to SKS and WER, and by philanthropic gifts in support of medical research at Marshfield Clinic. It was also supported by the National Institutes of Health-Clinical and Translational Science Award (CTSA) program, funded through the National Center for Advancing Translational Sciences grant UL1TR000427.

\section{Compliance with ethical standards}

Conflict of interest The authors declare that they have no conflict of interest.

Publisher's note Springer Nature remains neutral with regard to jurisdictional claims in published maps and institutional affiliations.

\section{References}

1. Lowy FD. Staphylococcus aureus infections. N Engl J Med. 1998;339:520.

2. Tak T, Reed KD, Haselby RC, McCauley CS Jr, Shukla SK. An update on the epidemiology, pathogenesis and management of infective endocarditis with emphasis on Staphylococcus aureus. WMJ. 2002;101:24-33.

3. John J, Shukla SK. Staphylococcus aureus. In: Mayhall CG, editor. Hospital epidemiology and infection control. 4th ed. Philadelphia: Lippincott Williams \& Wilkins; 2012. p. 385-409.

4. Naber CK. Staphylococcus aureus bacteremia: epidemiology, pathophysiology, and management strategies. Clin Infect Dis. 2009;48 (Suppl 4):S231-7.

5. Seilie ES, Bubeck Wardenburg J. Staphylococcus aureus poreforming toxins: the interface of pathogen and host complexity. Semin Cell Dev Biol. 2017;72:101-16.

6. Shukla SK, Karow ME, Brady JM, Stemper ME, Kislow J, Moore $\mathrm{N}$, et al. Virulence genes and genotypic associations in nasal carriage, community-associated methicillin-susceptible and methicillin-resistant USA400 Staphylococcus aureus isolates. J Clin Microbiol. 2010;48:3582-92.

7. Foster TJ. The MSCRAMM family of cell-wall-anchored surface proteins of gram-positive cocci. Trends Microbiol. 2019;27: 927-41.

8. Miller LS, Fowler VG, Shukla SK, Rose WE, Proctor RA. Development of a vaccine against Staphylococcus aureus invasive infections: evidence-based on human immunity, genetics, and bacterial evasion mechanisms. FEMS Microbiol Rev. 2020;44:123-53.

9. Ye Z, Vasco DA, Carter TC, Brilliant MH, Schrodi SJ, Shukla SK. Genome wide association study of SNP-, gene-, and pathwaybased approaches to identify genes influencing susceptibility to Staphylococcus aureus infections. Front Genet. 2014;5:125.

10. Minejima E, Mai N, Bui N, Mert M, Mack WJ, She RC, et al. Defining the breakpoint duration of Staphylococcus aureus bacteremia predictive of poor outcomes. Clin Infect Dis. 2020;70:566-73.

11. Shukla SK, Rose W, Schrodi SJ. Complex host genetic susceptibility to Staphylococcus aureus infections. Trends Microbiol. 2015;23:529-36.

12. Messina JA, Thaden JT, Sharma-Kuinkel BK, Fowler VG Jr. Impact of bacterial and human genetic variation on Staphylococcus aureus infections. PLoS Pathog. 2016;12:e1005330.

13. Oestergaard LB, Christiansen MN, Schmiegelow MD, Skov RL, Andersen PS, Petersen A, et al. Familial clustering of Staphylococcus aureus bacteremia in first-degree relatives: a Danish nationwide cohort study. Ann Intern Med. 2016;165:390-8.
14. Cyr DD, Allen AS, Du G-J, Ruffin F, Adams C, Thaden JT, et al. Evaluating genetic susceptibility to Staphylococcus aureus bacteremia in African Americans using admixture mapping. Genes Immun. 2017;18:95-9.

15. Scott WK, Medie FM, Ruffin F, Sharma-Kuinkel BK, Cyr DD, Guo S, et al. Human genetic variation in GLS2 is associated with development of complicated Staphylococcus aureus bacteremia. PLoS Genet. 2018;14:e1007667.

16. Gilchrist JJ, Mentzer AJ, Rautanen A, Pirinen M, Mwarumba S, Njuguna $\mathrm{P}$, et al. Genetic variation in VAC14 is associated with bacteremia secondary to diverse pathogens in African children. Proc Natl Acad Sci USA. 2018;115:E3601-3.

17. Askarian F, Wagner T, Johannessen M, Nizet V. Staphylococcus aureus modulation of innate immune responses through Toll-like (TLR), (NOD)-like (NLR) and C-type lectin (CLR) receptors. FEMS Microbiol Rev. 2018;42:656-71.

18. Netea MG, Wijmenga C, O'Neill LA. Genetic variation in Tolllike receptors and disease susceptibility. Nat Immunol. 2012;13: 535-42.

19. Stenzel W, Soltek S, Sanchez-Ruiz M, Akira S, Miletic H, Schluter $\mathrm{D}$, et al. Both TLR2 and TLR4 are required for the effective immune response in Staphylococcus aureus-induced experimental murine brain abscess. Am J Pathol. 2008;172:132-45.

20. Kawai T, Akira S. TLR signaling. Cell Death Differ. 2006;13: 816-25.

21. Picard C, Puel A, Bonnet M, Ku CL, Bustamante J, Yang K, et al. Pyogenic bacterial infections in humans with IRAK-4 deficiency. Science. 2003;299:2076-9.

22. Yao Q. Nucleotide-binding oligomerization domain containing 2: structure, function, and diseases. Semin Arthritis Rheum. 2013;43:125-30.

23. Stappers MH, Thys Y, Oosting M, Plantinga TS, Ioana M, Reimnitz P, et al. TLR1, TLR2, and TLR6 gene polymorphisms are associated with increased susceptibility to complicated skin and skin structure infections. J Infect Dis. 2014;210:311-8.

24. Stappers MH, Oosting M, Ioana M, Reimnitz P, Mouton JW, Netea MG, et al. Genetic variation in TLR10, an inhibitory Tolllike receptor, influences susceptibility to complicated skin and skin structure infections. J Infect Dis. 2015;212:1491-9.

25. Stappers MH, Thys Y, Oosting M, Plantinga TS, Ioana M, Reimnitz P, et al. Polymorphisms in cytokine genes IL6, TNF, IL10, IL17A and IFNG influence susceptibility to complicated skin and skin structure infections. Eur J Clin Microbiol Infect Dis. 2014;33:2267-74.

26. Fowler VG Jr, Miro JM, Hoen B, Cabell CH, Abrutyn E, Rubinstein E, et al. Staphylococcus aureus endocarditis: a consequence of medical progress. JAMA. 2005;293:3012-21.

27. Sim NL, Kumar P, Hu J, Henikoff S, Schneider G, Ng PC. SIFT web server: predicting effects of amino acid substitutions on proteins. Nucleic Acids Res. 2012;40:W452-7.

28. Adzhubei IA, Schmidt S, Peshkin L, Ramensky VE, Gerasimova A, Bork P, et al. A method and server for predicting damaging missense mutations. Nat Methods. 2010;7:248-9.

29. The Encode Project Consortium. An integrated encyclopedia of DNA elements in the human genome. Nature. 2012;489:57-74.

30. Frade AF, Pissetti CW, Ianni BM, Saba B, Lin-Wang HT, Nogueira LG, et al. Genetic susceptibility to Chagas disease cardiomyopathy: involvement of several genes of the innate immunity and chemokine-dependent migration pathways. BMC Infect Dis. 2013;13:587.

31. Ovsyannikova IG, Haralambieva IH, Vierkant RA, Pankratz VS, Jacobson RM, Poland GA. The role of polymorphisms in Toll-like receptors and their associated intracellular signaling genes in measles vaccine immunity. Hum Genet. 2011;130:547-61. 
32. Kimman TJ, Banus S, Reijmerink N, Reimerink J, Stelma FF, Koppelman GH, et al. Association of interacting genes in the Tolllike receptor signaling pathway and the antibody response to pertussis vaccination. PLoS One. 2008;3:e3665.

33. Stark JR, Wiklund F, Grönberg H, Schumacher F, Sinnott JA, Stampfer MJ, et al. Toll-like receptor signaling pathway variants and prostate cancer mortality. Cancer Epidemiol Biomark Prev. 2009;18:1859-63.

34. Miyake A, Kou I, Takahashi Y, Johnson TA, Ogura Y, Dai J, et al. Identification of a susceptibility locus for severe adolescent idiopathic scoliosis on chromosome 17q24.3. PLos One. 2013;8: e72802.

35. Taylor BD, Darville T, Ferrell RE, Kammerer CM, Ness RB, Haggerty CL. Variants in Toll-like receptor 1 and 4 genes are associated with Chlamydia Trachomatis among women with pelvic inflammatory disease. J Infect Dis. 2012;205:603-9.

36. Song Z, Tong C, Sun Z, Shen Y, Yao C, Jiang J, et al. Genetic variants in the TIRAP gene are associated with increased risk of sepsis-associated acute lung injury. BMC Med Genet. 2010;11:168.

37. Hawn TR, Scholes D, Li SS, Wang H, Yang Y, Roberts PL, et al. Toll-like receptor polymorphisms and susceptibility to urinary tract infections in adult women. PLoS One. 2009;4:e5990.

38. Hawn TR, Dunstan SJ, Thwaites GE, Simmons CP, Thuong NT, Lan NT, et al. A polymorphism in Toll-interleukin 1 receptor domain containing adaptor protein is associated with susceptibility to meningeal tuberculosis. J Infect Dis. 2006;194:1127-34.

39. Kullar R, McKinnell JA, Sakoulas G. Avoiding the perfect storm: the biologic and clinical case for reevaluating the 7-day expectation for methicillin-resistant Staphylococcus aureus bacteremia before switching therapy. Clin Infect Dis. 2014;59:1455-61.

40. Rose WE, Eickhoff JC, Shukla SK, Pantrangi M, Rooijakkers S, Cosgrove SE, et al. Elevated serum interleukin-10 at time of hospital admission is predictive of mortality in patients with Staphylococcus aureus bacteremia. J Infect Dis. 2012;206:1604-11.

41. Jenkins KA, Mansell A. TIR-containing adaptors in Toll-like receptor signalling. Cytokine. 2010;49:237-44.

42. Krishna S, Miller LS. Host-pathogen interactions between the skin and Staphylococcus aureus. Curr Opin Microbiol. 2012;15:28-35.

43. Turvey SE, Speert DP. Recurrent systemic pneumococcal disease and IRAK4 deficiency. Pediatr Infect Dis J. 2007;26:1074.

44. Hamann L, Kumpf O, Schuring RP, Alpsoy E, Bedu-Addo G, Bienzle U, et al. Low frequency of the TIRAP S180L polymorphism in Africa, and its potential role in malaria, sepsis, and leprosy. BMC Med Genet. 2009;10:65.

45. Schmaler M, Jann NJ, Ferracin F. Landmann RT and B cells are not required for clearing Staphylococcus aureus in systemic infection despite a strong TLR2-MyD88-dependent T cell activation. J Immunol. 2011;186:443-52.

46. Khor CC, Vannberg FO, Chapman SJ, Guo H, Wong SH, Walley AJ, et al. CISH and susceptibility to infectious diseases. N Engl J Med. 2010;362:2092-101.

47. Adhikari RP, Ajao AO, Aman MJ, Karauzum H, Sarwar J, Lydecker AD, et al. Lower antibody levels to Staphylococcus aureus exotoxins are associated with sepsis in hospitalized adults with invasive $S$. aureus infections. J Infect Dis. 2012;206:915-23.

48. Aken BL, Achuthan P, Akanni W, Amode MR, Bernsdorff F, Bhai J, et al. Ensembl 2017. Nucleic Acids Res. 2017;45:D635-42.

49. Rosenbloom KR, Sloan CA, Malladi VS, Dreszer TR, Learned K, Kirkup VM, et al. ENCODE data in the UCSC Genome Browser: year 5 update. Nucleic Acids Res. 2013;41:D56-63.

50. Lesurf R, Cotto KC, Wang G, Griffith M, Kasaian K, Jones SJ, et al. ORegAnno 3.0: a community-driven resource for curated regulatory annotation. Nucleic Acids Res. 2016;44:D126-32.

51. Bhattacharya A, Ziebarth JD, Cui Y. PolymiRTS Database 3.0: linking polymorphisms in microRNAs and their target sites with human diseases and biological pathways. Nucleic Acids Res. 2014;42:D86-91.

52. Nakagome S, Mano S, Kozlowski L, Bujnicki JM, Shibata H, Fukumaki Y, et al. Crohn's disease risk alleles on the NOD2 locus have been maintained by natural selection on standing variation. Mol Biol Evol. 2012;29:1569-85.

53. Semlali A, Parine NR, Al-Numair NS, Almutairi M, Hawsawi YM, Amri AA, et al. Potential role of Toll-like receptor 2 expression and polymorphisms in colon cancer susceptibility in the Saudi Arabian population. OncoTargets Ther. 2018;11:8127-41.

54. Firth D. Bias reduction of maximum likelihood estimates. Biometrika. 1993;80:27-38.

55. Chang CC, Chow CC, Tellier LC, Vattikuti S, Purcell SM, Lee JJ. Second-generation PLINK: rising to the challenge of larger and richer datasets. Gigascience. 2015;4:7.

56. Schaid DJ, Rowland CM, Tines DE, Jacobson RM, Poland GA. Score tests for association between traits and haplotypes when linkage phase is ambiguous. Am J Hum Genet. 2002;70:425-34. 